\title{
EFFECT OF TBC COATED PISTON CROWN ON THE EMISSION OF TWO STROKE SI ENGINE
}

\author{
Liladhar Naphade ${ }^{1}$, P. Homesh Naidu ${ }^{2}$, Aditya Falke ${ }^{3}$, Abhishek Dhone ${ }^{4}$, Abhinav Pande \\ ${ }^{I}$ Student, Mechanical Engineering Department, Rastrasant Tukdoji Maharaj University, Nagpur, India \\ ${ }^{2}$ Student, Mechanical Engineering Department, Rastrasant Tukdoji Maharaj University, Nagpur, India \\ ${ }^{3}$ Student, Mechanical Engineering Department, Rastrasant Tukdoji Maharaj University, Nagpur, India \\ ${ }^{4}$ Student, Mechanical Engineering Department, Rastrasant Tukdoji Maharaj University, Nagpur, India \\ ${ }^{5}$ Student, Mechanical Engineering Department, Rastrasant Tukdoji Maharaj University, Nagpur, India
}

\begin{abstract}
Conservation of energy and improvement of efficiency has always been the major area of concern for the automobile engineering. During the combustion stroke on an IC engine, a lot of heat is generated inside the combustion chamber, nearly thirty three percent of heat is absorbed by the cylinder walls, valves, piston, and etc. thirty three percent goes to the surrounding buy exhaust gases, the rest thirty four percent is used for the shaft work. By this study we aim to minimize the emission to the surrounding from the combustion chamber. The transfer of heat can be minimized by applying Thermal barrier coating on the various components of I.C. engine. A TBC is a ceramic material usually consisting of duplex structure the top coat and the bond coat. After studying various journals, we have found some TBC material candidate which could be used in our experiment. To find the optimal material, the method called as Simple Additive Weighted (SAW) method is used which is a non-traditional optimizing method under the category of Multiple Attribute Decision Making method.
\end{abstract}

Keywords: Simple Additive Weighted Method, Multiple Attribute Decision Making, Thermal Barrier Coatings, Alumina, Weight, non-traditional methods

\section{INTRODUCTION}

Selection of material is a key factor for any industry. To solve this complex and important problem we must go for an analytical method rather than other initiative decisions. We had shortlisted a list of materials and their corresponding properties of utmost use. The demands of the properties of ideal material were different. Some should be high and some should be low. Now the question arises - Which material is best suited? There are many traditional optimizing methods like Linear Programming (LPP), Simplex method, Assignment method. But these cannot be applied because the variables were more than the requirement of the method. Simplex can be employed but the set of equations and its degree would be very high which would take years to calculate the solution. This is where the non-traditional optimizing methods come into the scenario. Here we have used Multiple Attribute Decision Making (MADM) method. Various methods come under this category like SAW/WSM, WPM, AHP, TOPSIS, and PEOMETHBE. We have used Simple Additive Weighting (SAW) method; one of the simplest methods of MADM.

The paper shows a real application of selection of material by using one of the MADM model. It is called Simple Additive Weighted method. Here, we have applied six attribute on eight alternatives that they are necessarily required for choosing the best suited material of TBC (Thermal Barrier Material) according to the rank.

\section{METHODOLOGY}

Simple Additive Weighting (SAW) is more oftenly used MADM method. It is also known as weighted linear combination method. This method is based on weighted average. A value is calculated for each alternative by multiplying the given value of each attribute with the weights of relative importance. And then the rank of the sum of scores of the attributes of each alternatives gives us the best among the given. Process of SAW consists of the following steps:

Step I:

1) Using the Saaty's 1-9 scale [2] form a pair-wise matrix of size $(n * n)$ of the attributes as in Table 1 . The table is used to compare each attribute with the other attributes individually.

Table 1: Saaty's 1-9 scale

\begin{tabular}{|l|l|l|}
\hline & $\begin{array}{l}\text { Numeric } \\
\text { Rating }\end{array}$ & Reciprocal \\
\hline Extreme importance & 9 & $1 / 9$ \\
\hline Very strong to extremely & 8 & $1 / 8$ \\
\hline Very strong importance & 7 & $1 / 7$ \\
\hline Strongly to very strong & 6 & $1 / 6$ \\
\hline Strong importance & 5 & $1 / 5$ \\
\hline Moderately to strong & 4 & $1 / 4$ \\
\hline Moderate importance & 3 & $1 / 3$ \\
\hline Equally to moderately & 2 & $1 / 2$ \\
\hline Equal importance & 1 & 1 \\
\hline
\end{tabular}


2) For each and every comparison, decide which of the two attribute has more importance, then designate a value to it. The less important attribute has score reciprocal of the more important attribute score. Compute the same for each comparison individually.

3) Weighted sum matrix is obtained by multiplication of the comparison matrix with the weight matrix.

4) Now divide all the cells of the weighted sum matrix by their individual weights.

5) Obtain the aggregate of this particular value to obtain $\alpha_{\max }$.

6) Determine the Consistency Index (CI):

$$
C I=\frac{\alpha \max -1}{n-1}, \text { where } \mathrm{n} \text { is the matrix size. }
$$

7) Determine the Consistency Ratio (CR):

$$
C R=\frac{C I}{R I} \text {, where } \mathrm{RI} \text { is the Random Consistency }
$$

8) If the CR does not exceed 0.01, it is acceptable.

The value of RI is taken from the table:

Table 2: Values of RI

\begin{tabular}{|l|l|}
\hline Size of matrix & Random consistency \\
\hline 1 & 0 \\
\hline 2 & 0 \\
\hline 3 & 0.58 \\
\hline 4 & 0.9 \\
\hline 5 & 1.12 \\
\hline 6 & 1.24 \\
\hline 7 & 1.32 \\
\hline 8 & 1.41 \\
\hline 9 & 1.45 \\
\hline 10 & 1.49 \\
\hline
\end{tabular}

\section{Step II:}

Formulate the decision matrix $\left(m^{*} n\right)$ and obtain the normalized decision matrix.

For maximization of the objective function:

$$
N_{i j}=r_{i j} / r_{j}^{*}, \mathrm{i}=1, \ldots \mathrm{m} \text { and } \mathrm{j}=1, \ldots \mathrm{n}
$$

And for minimization of the objective function:

$$
N_{i j}=\mathrm{r}_{\mathrm{j}}^{\mathrm{min}} / \mathrm{r}_{\mathrm{ij}}, \mathrm{i}=1, \ldots \mathrm{m} \text { and } \mathrm{j}=1, \ldots \mathrm{n}
$$

Calculate each alternative, $A_{i}$ by the formula:

$$
A_{i}=\Sigma W_{j} x_{i j}
$$

Where $\mathrm{x}_{\mathrm{ij}}=$ value of the $\mathrm{i}^{\text {th }}$ alternative w.r.t. the $\mathrm{j}^{\text {th }}$ attribute, $\mathrm{W}_{\mathrm{j}}=$ weighted attribute.

\section{CAlCulation}

By using six attribute given below we want to sort eight materials which can be used for coating the piston. These attribute are given in the Table 3:

Table 3: Attribute name

\begin{tabular}{|l|l|}
\hline Attribute & Explanation \\
\hline A1 & Young's Modules \\
\hline A2 & Thermal diffusivity \\
\hline A3 & Thermal conductivity \\
\hline A4 & Heat capacity \\
\hline A5 & Poisson's number \\
\hline A6 & Density \\
\hline
\end{tabular}

The weights of the attribute can be calculated by using comparison matrix. Data was gathered by the research paper which attribute has more weightage than other attribute. It is given in Table 4 by using scale values of the range $1-3$.

Table 4: Specifying the scale values

\begin{tabular}{|l|l|}
\hline $\begin{array}{l}\text { Intensity of } \\
\text { importance }\end{array}$ & Definition \\
\hline 1 & Equal importance \\
\hline 2 & Strong importance \\
\hline 3 & Extremely high importance \\
\hline
\end{tabular}

The Table 5 indicates the relative importance of the attributes in the columns compared to the attributes in the rows.

Table 5: Comparison Matrix

\begin{tabular}{|c|c|c|c|c|c|c|}
\hline Attribute & A1 & A2 & A3 & A4 & A5 & A6 \\
\hline A1 & 1.00 & 0.50 & 0.33 & 0.33 & 0.50 & 0.50 \\
\hline A2 & 2.00 & 1.00 & 0.50 & 0.50 & 1.00 & 0.50 \\
\hline A3 & 3.00 & 2.00 & 1.00 & 1.00 & 0.50 & 2.00 \\
\hline A4 & 3.00 & 2.00 & 1.00 & 1.00 & 2.00 & 1.00 \\
\hline A5 & 2.00 & 1.00 & 2.00 & 0.50 & 1.00 & 3.00 \\
\hline A6 & 2.00 & 2.00 & 0.50 & 1.00 & 0.33 & 1.00 \\
\hline
\end{tabular}

Weights of attribute by comparison matrix:

1) Apply $(\mathrm{X})^{1 / 6}$ to each single cell of comparison matrix.

2) Product of each row.

3) Take the summation of product column obtained.

4) Weight, $W=\frac{\text { product of eac } h \text { row }}{\text { summation of product coloumn }}$ 


\begin{tabular}{|l|l|l|l|l|l|l|l|l|}
\hline Attribute & A1 & A2 & A3 & A4 & A5 & A6 & $\sum$ & Weights \\
\hline A1 & 1.00 & 0.8908 & 0.8312 & 0.8312 & 0.8908 & 0.8908 & 0.4883 & 0.07603 \\
\hline A2 & 1.1224 & 1.00 & 0.8908 & 0.8908 & 1.00 & 0.8908 & 0.7933 & 0.123522 \\
\hline A3 & 1.2009 & 1.1224 & 1.00 & 1.00 & 0.8908 & 1.1224 & 1.3476 & 0.209831 \\
\hline A4 & 1.2009 & 1.1224 & 1.00 & 1.00 & 1.1224 & 1.00 & 1.5128 & 0.2354 \\
\hline A5 & 1.1224 & 1 & 1.1224 & 0.8908 & 1.00 & 1.2009 & 1.3476 & 0.2098 \\
\hline A6 & 1.1224 & 1.1224 & 0.8908 & 1.00 & 0.8312 & 1.00 & 0.9327 & 0.1452 \\
\hline Total & & & & & & & 6.4223 & 1.00 \\
\hline
\end{tabular}

\section{Test of Consistency}

If the calculated rate of consistency is less than 0.1 then it indicated that it is sufficiently consistent. The following are steps to test the consistency:

\section{Step 1: To Calculate Weights}

Weighted Sum Vector (WSM):

\begin{tabular}{|c|c|c|c|c|c|c|c|c|c|}
\hline 1.00 & 0.50 & 0.33 & 0.33 & 0.50 & 0.50 & \multirow{6}{*}{$\times$} & 0.07603 & \multirow{6}{*}{$=$} & 0.4621 \\
\hline 2.00 & 1.00 & 0.50 & 0.50 & 1.00 & 0.50 & & 0.123522 & & 0.7805 \\
\hline 3.00 & 2.00 & 1.00 & 1.00 & 0.50 & 2.00 & & 0.209831 & & 1.3155 \\
\hline 3.00 & 2.00 & 1.00 & 1.00 & 2.00 & 1.00 & & 0.2354 & & 1.4851 \\
\hline 2.00 & 1.00 & 2.00 & 0.50 & 1.00 & 3.00 & & 0.2098 & & 1.4582 \\
\hline 2.00 & 2.00 & 0.50 & 1.00 & 0.33 & 1.00 & & 0.1452 & & 0.9537 \\
\hline
\end{tabular}

From this we get the consistency vector. Round off this CV up to four decimal points. Now, each of the cells is divided by each other cell. For e.g., when 0.4621 is divided by 0.07603 of $1^{\text {st }}$ row, we get 6.0802 as the answer and so on the calculations are carried out.

\begin{tabular}{|c|c|c|c|c|}
\hline 0.4621 & \multirow{6}{*}{$\div$} & 0.07603 & \multirow{6}{*}{$=$} & 6.0802 \\
\hline 0.7805 & & 0.123522 & & 6.3198 \\
\hline 1.3155 & & 0.209831 & & 6.2702 \\
\hline 1.485 & & 0.2354 & & 6.3084 \\
\hline 1.4582 & & 0.2098 & & 6.9504 \\
\hline 0.9537 & & 0.1452 & & 6.5681 \\
\hline
\end{tabular}

$$
\alpha_{\max }=\frac{6.0802+6.3198+6.2702+6.3084+6.9504+6.5681}{6}
$$

$$
=6.4161
$$

Amount of Consistency Index (CI):

$$
\text { C.I }=\frac{\alpha \max -n}{n-1} \quad \mathrm{n}=\text { No. } \text { of attribute }
$$

$$
=\frac{6.4161-6}{6-1}=0.08322
$$

Consistency rate $\mathrm{C} . \mathrm{R}=\frac{\text { Consistency Index (C.I) }}{\text { Random Index (RI) }}$

$$
=\frac{0.08322}{1.24}=0.06711
$$

The consistency ratio obtained is less than 0.10 ; therefore the scale values assumed earlier are correct. Our data collected regarding the materials and their properties is given below:

\begin{tabular}{|l|l|}
\hline Alternative & Explanation \\
\hline P1 & 3YSZ \\
\hline P2 & Mullite \\
\hline P3 & $\mathrm{Al}_{2} \mathrm{O}_{3}$ \\
\hline P4 & $\mathrm{NiCrAl}$ \\
\hline P5 & $\mathrm{MgPSZ}$ \\
\hline P6 & YPSZ \\
\hline P7 & $\mathrm{CaZrO}_{3}$ \\
\hline P8 & $\mathrm{MgZrO}_{3}$ \\
\hline
\end{tabular}

\begin{tabular}{|l|l|l|l|l|l|l|}
\hline & A1 & A2 & A3 & A4 & A5 & A6 \\
\hline P1 & 21 & 11.5 & 2.12 & 640 & 0.29 & 5711 \\
\hline P2 & 30 & 5.2 & 3.3 & 950 & 0.25 & 2800 \\
\hline P3 & 30 & 9.6 & 1.8 & 775 & 0.26 & 3696 \\
\hline P4 & 90 & 10.3 & 3.88 & 764 & 0.27 & 7870 \\
\hline P5 & 46 & 10 & 1.8 & 650 & 0.23 & 5600 \\
\hline P6 & 11.29 & 10.9 & 1.4 & 620 & 0.25 & 5650 \\
\hline P7 & 87 & 11.5 & 14.6 & 698 & 0.21 & 4680 \\
\hline P8 & 86 & 8.01 & 15.3 & 650 & 0.20 & 5600 \\
\hline Obj. & $\max$ & $\max$ & Min & max & Min & min \\
\hline Weight & 0.07627 & 0.1234 & 0.2097 & 0.2394 & 0.2097 & 0.14541 \\
\hline
\end{tabular}




\section{Step 2: Normalization of Matrix}

For maximization of the objective function:

$$
N_{i j}=\mathrm{r}_{\mathrm{ij} /} \mathrm{r}_{\mathrm{j}}^{*}, \mathrm{i}=1 \text { to } 8 \text { and } \mathrm{j}=1 \text { to } 6
$$

And for minimization of the objective function:

$$
N_{i j}=\mathrm{r}_{\mathrm{j}}^{\min } / \mathrm{r}_{\mathrm{ij}}, \mathrm{i}=1 \text { to } 8 \text { and } \mathrm{j}=1 \text { to } 6
$$

\begin{tabular}{|l|l|l|l|l|l|l|}
\hline & A1 & A2 & A3 & A4 & A5 & A6 \\
\hline P1 & 0.233 & 1 & 0.6603 & 0.6736 & 0.8 & 0.4902 \\
\hline P2 & 0.344 & 0.460 & 0.4242 & 1 & 0.8 & 1 \\
\hline P3 & 0.344 & 0.834 & 0.78 & 0.8157 & 0.7692 & 0.7575 \\
\hline P4 & 1 & 0.895 & 0.3608 & 0.8042 & 0.7407 & 0.3557 \\
\hline P5 & 0.511 & 0.8695 & 0.78 & 0.6842 & 0.8695 & 0.5 \\
\hline P6 & 0.125 & 0.9478 & 1 & 0.6526 & 0.8 & 0.495 \\
\hline P7 & 0.967 & 1 & 0.0959 & 0.7347 & 0.9523 & 0.585 \\
\hline P8 & 0.956 & 06954 & 0.0915 & 0.6842 & 1 & 0.5 \\
\hline
\end{tabular}

\begin{tabular}{|l|l|l|l|l|l|l|}
\hline & A1 & A2 & A3 & A4 & A5 & A6 \\
\hline P1 & 0.0177 & 0.123481 & 0.1384 & 0.1585 & 0.1677 & 0.0712 \\
\hline P2 & 0.0262 & 0.0568 & 0.889 & 0.2354 & 0.1677 & 0.14541 \\
\hline P3 & 0.262 & 0.1030 & 0.1635 & 0.192 & 0.1613 & 0.1101 \\
\hline P4 & 0.0762 & 0.1106 & 0.0765 & 0.1893 & 0.1553 & 0.0517 \\
\hline P5 & 0.0389 & 0.1073 & 0.635 & 0.1610 & 0.1823 & 0.0727 \\
\hline P6 & 0.0095 & 0.1170 & 0.2097 & 0.1536 & 0.1677 & 0.720 \\
\hline P7 & 0.0737 & 0.1234 & 0.0201 & 0.1729 & 0.1997 & 0.0851 \\
\hline P8 & 0.729 & 0.086 & 0.0191 & 0.1616 & 0.2097 & 0.0727 \\
\hline
\end{tabular}

The summation of the attributes with their rank is as follows:

\begin{tabular}{|l|l|l|}
\hline Alternative & Summation & Rank \\
\hline P1 & 0.6769 & $5^{\text {th }}$ \\
\hline P2 & 0.07201 & $4^{\text {th }}$ \\
\hline P3 & 0.9937 & $1^{\text {st }}$ \\
\hline P4 & 0.6587 & $7^{\text {th }}$ \\
\hline P5 & 0.7257 & $3^{\text {rd }}$ \\
\hline P6 & 0.7295 & $2^{\text {nd }}$ \\
\hline P7 & 0.6749 & $6^{\text {th }}$ \\
\hline P8 & 0.6220 & $8^{\text {th }}$ \\
\hline
\end{tabular}

Thus the best suited material obtained is P3, i.e.; Alumina

\section{CONCLUSION}

In this paper, we have explained the MADM method for selection of material. By the application of this method, the best suited material obtained is P3, i.e.; Alumina. With the use of simple software, the calculations could be speed up. The drawback of the method is that some attribute might have a qualitative property or have an uncertain structure which might be difficult to measure.

\section{Step 3: Multiply Attributes Value with its Respective Weight.}

The simple additive weighting method evaluates each alternative, Ai. By the following formula:

$$
A_{i}=\Sigma W_{j} x_{i j}
$$

where $\mathrm{x}_{\mathrm{ij}}=$ value of the $\mathrm{i}^{\text {th }}$ alternative w.r.t. the $\mathrm{j}^{\text {th }}$ attribute, $\mathrm{W}_{\mathrm{j}}=$ weighted attribute,

$\mathrm{i}=1$ to 6 and $\mathrm{j}=1$ to 8 .

The final matrix is as follows:

\section{REFERENCES}

[1]. Alireza Afshari, Majid Mojahed and Rosnah Mohd Yusuff, (2010), "Simple Additive Weighting approach to Personnel Selection problem", International Journal of Innovation, Management and Technology, Vol. 1, No. 5, ISSN: 2010-0248

[2]. Melvin Alexander, (2012), "Decision-Making using the Analytic Hierarchy Process (AHP) and SAS”, SESUG 2012 [3]. Xueqiang Cao "Development of New Thermal Barrier Coating Materials for Gas Turbines", (Diss ., Bochum, Univ., 2004)

[4]. Carlos G. Levi, "Emerging Materials and Processes for Thermal Barrier Systems", March, 2004

[5]. K. Thiruselvam, "Thermal Barrier Coatings in Internal Combustion Engine" , Journal of Chemical and Pharmaceutical Sciences ISSN: 0974-2115 